\title{
TOOMPEA HILL STABILITY AND TALLINN AREA SUBSIDENCE
}

\author{
JÜRI-RIVALDO PASTARUS, Dr. Eng., asoc. prof. \\ Tallinn Technical University, Department of Mining \\ 82 Kopli Str., Tallinn, 10412, ESTONIA \\ Phone: 6203850, Fax: (372) 6203696
}

\begin{abstract}
This paper analyses the deformation of the Toompea Hill, using the theoretical and numerical modeling. Analysis showed that the Toompea Hill deformation is connected with the subsidence of the territory of Tallinn. Numerical modeling, using onedimensional model and FLAC-program evaluated the calculations. Total deformations of the layers and surface subsidence are quite small and do not exceed $7 \mathrm{~mm}$, owen to the consolidated Vendian sandstone and clays.
\end{abstract}

\section{Introduction}

The capital city of Estonia Tallinn is situated on the southern coast of the Gulf of Finland in the Baltic Sea. On the Toompea Hill situated in the center of Tallinn there are several natural, ancient architectural and historical monuments. It has become apparent that the processes in the rock mass caused an unfavorable invironmental side effect, accompanied by deformation of the Toompea Hill.

Identifications of the reasons of the Toompea Hill's deformation and give the prognoses is the main aim of the present work.

For the feasibility study stability problems were investigated. It was decided to perform numerical modeling analysis using the FLAC-program (Fast Lagrangian Analysis of Continua) (FLAC 1995). It is suitable for stability analysis. Here, the methodology for rock mechanics modeling in data limited conditions were used (Starfield \& Cundall 1988).

For the first time, a complex method of preliminary analysis before the modeling has been proposed. This method enables to improve the quality of the investigations.

The selection of all rock mass properties was based on the complex method field observations, laboratory tests and RMR-system (Hoek \& Brown 1980).

Using the above-mentioned methods, it may to get the excellence results.

\section{Geology}

Pre-Cambrian cristalline igneous and metamorphic rocks form the base of the area of Tallinn. Lower Paleozoic sedimentary rocks lie on the crystalline base rock; whish is covered with Quaternary clastic rocks (Figure1). During the Pre-Quaternary period, ancient valleys were incised through Cambrian clays and the underlying sandstones. Later mainly fluvio-glacial sand-and- gravel deposits, Quaternary lacustrineglacial flowing and plastic clays, filled the ancient valleys.

Confined Cambrian-Vendian aquifer of the thickness of $60-70 \mathrm{~m}$ is one of the water source for Tallinn. Owing to strontg underground pumping on the center of cone of depression the lowering of the potentiometric surface $(30 \mathrm{~m})$ attains. 


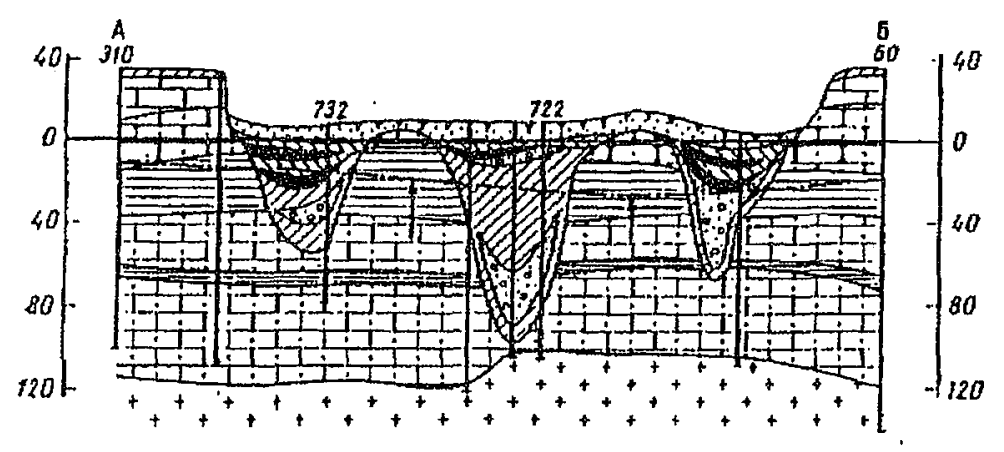

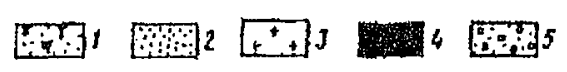

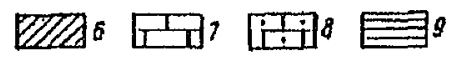

Figure 1. Cross-section of the Toompea Hill

1 - soil; 2 - sand; 3 - crystalline rocks; 4 - flowing-plastic clay; 5 - sand and gravel; 6 - moraine loam; 7 - hard limestone; 8 - solid sandstone; 9 - solid clay

Unconfined Ordovician-Cambrian aquifer-aquitard system is separated from Cambrian-Vendian system by $25-35 \mathrm{~m}$ thick consolidated clays. $18-22 \mathrm{~m}$ thick sandstone layer represents the aquifer. The water table fluctuates from 0.4 to $1.0 \mathrm{~m}$.

The height of the Toompea Hill is $24 \mathrm{~m}$ ( $47 \mathrm{~m}$ above sea level) and the dimensions in different directions are following: NE-SW $-300 \mathrm{~m}, \mathrm{NW}-\mathrm{SE}-200 \mathrm{~m}$. It is represented by Quaternary, Ordovician and Cambrian sediments (Figure 2).

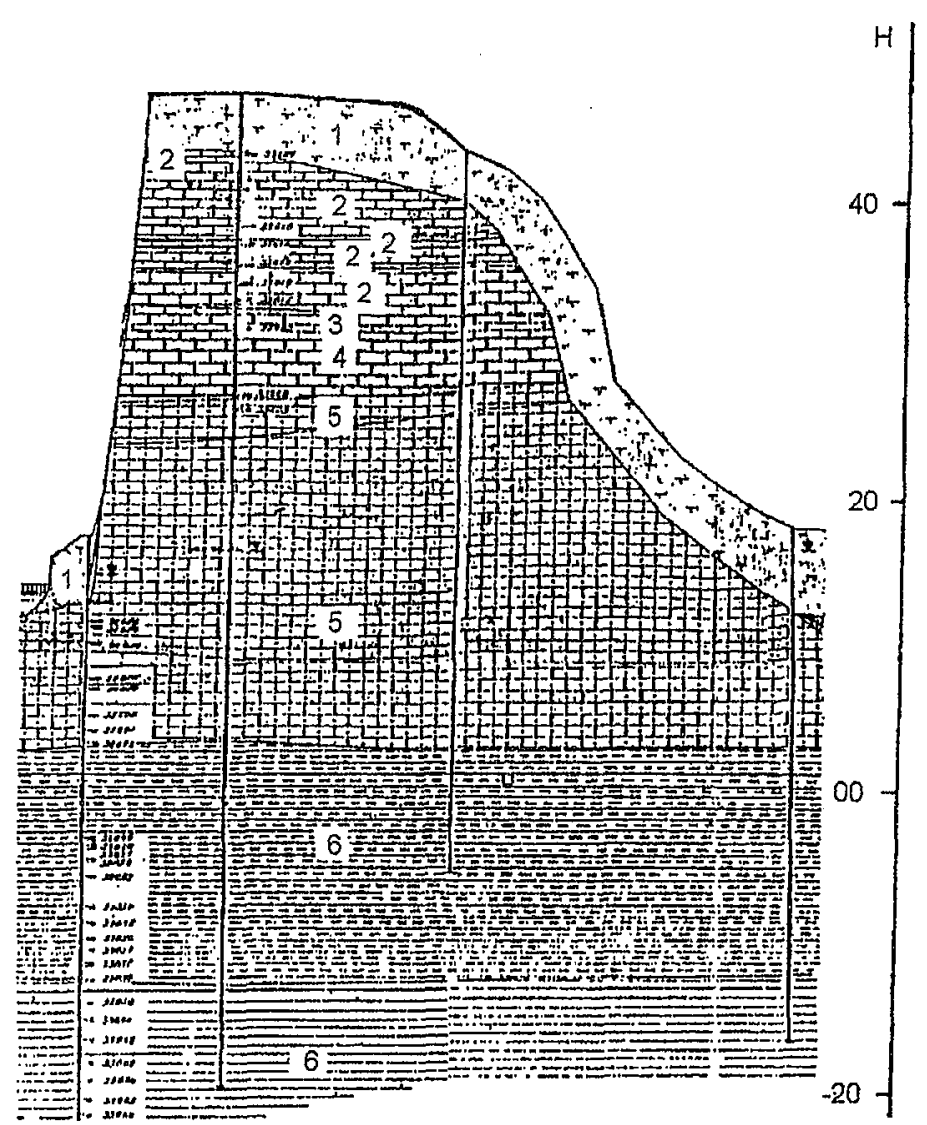

Figure 2. Cross-section of the Toompea Hill

1 - Quaternary sediments; 2 - hard limestone, 3 - soft sandstone; 4 -argillite; 5 - sandstone; 6 clay. 
Field investigations were carried out by means of a boring program. The number of boring holes was 6 bored at different depth from 26 to $68 \mathrm{~m}$. Toompea Hill is situated between the ancient burried valleys (see Figure 1).

On the Toompea Hill there are two aquifer-aquitard systems. Surface water is in the Quaternary sediments, on the top of the hill. Ordovician aquifer-aquitard system is situated in limestones and dolomites, where argellite clay layer forms a waterproof bottom. It is feed on the water from rain and snow, which infiltrates into terrain.

\section{Preliminary analysis}

Preliminary analysis enables to simplify and quicken the further modeling, improve the quality of the modeling.

Based on the geological investigations, analyses shows that the subsidence of territory of Tallinn is mainly caused by Ordovician-Cambrian and Cambrian-Vendian aquifer-aquitard systems. Consequently, the Toompea Hill deformations are connected with the subsidence of the territory of Tallinn. Performed investigations showes that:

a) The hydraulic conductivity of the aquitards is at least 2 orders of magnitude less than the hydraulic conductivity in the aquifer. It can be assumed that flow in aquifer is horizontal and leakage in the aquitards is vertical. Consequently, the application of a one-dimensional flow theory is adequate, developed by K.Terzaghi (Freeze \& Cherry 1979).

b) The stress field existing at depth is one-dimensional, changes in the horizontal stress field are very small and it can be assumed that they are negligible.

c) The weight of overburden rocks remains mainly constant through time.

The applicability of one-dimensional model depends on the physical substance of the modeled processes and was demonstrated by special investigations (Arbeiter et al. 1982, Freeze \& Cherry 1979).

\section{Theoretical model}

On the bases of the investigations, performed in Estonia, the total subsidence of the territory of Tallinn can be calculated by following formula (Arbeiter et al. 1982, Vallner \& Lutsar 1966):

$$
N(t)=-A(t)+B(p)+C(p)+D(t)+E(t)+F(t)+G(p)+K(t)+S(t)
$$

where $N(t)$ - total subsidence of the territory of Tallinn; $A(t)$ - surface displacement, caused by the tectonic processes; $B(p)$ - surface displacement, caused by the atmospheric pressure; $C(p)$ - unconfined aquifer elastic deformation, caused by the decrease of the water table; $D(t)$ - unconfined aquitard plastic deformation, caused by the decrease of the water table; $E(t)$ - soil compaction, caused by the buildings; $F(t)$ - soil compaction, caused by the vibrations; $G(p)$ - confined aquifer elastic deformation, caused by the decrease of the potentiometric surface; $K(t)$ - confined aquitard plastic deformation, caused by the decrease of the potentiometric surface; $S(t)$ - clay compaction in ancient buried valleys.

The influence of the different factors on the surface subsidence is represented in Table 1.

Analysis showed that the subsidence of the territory of Tallinn mainly depends on the behavior of Ordovician-Cambrian and Cambrian-Vendian aquifer-aquitqrd systems. 
Influence of the different factors on the total subsidence of the territory of Tallinn between the buried valleys

\begin{tabular}{lr}
\hline Parameter & Value \\
\hline$A(t)$ - surface displacement, caused by the tectonic processes, mm $/$ year & -1.7 \\
$B(p)$ - surface displacement, caused by the atmospheric pressure, mm & $0.1-0.2$ \\
$C(p)$ - Ordovician-Cambrian aquifer elastic deformation, mm & $0.5-1.0$ \\
$D(t)$ - Ordovician-Cambrian aquitard plastic deformation, mm/year & $<0.1$ \\
$\mathrm{E}(\mathrm{t})$ - soil compaction, caused by buildings, mm & 100 \\
$F(t)$ - soil compaction, caused by vibrations, mm & - \\
$G(p)$ - Cambrian-Vendian aquifer elastic deformation, mm & $1.0-2.0$ \\
$K(t)$ - Cambrian-Vendian aquitard plastic deformation, mm & $30-50$ \\
\hline
\end{tabular}

\section{Model properties}

The selection of all rock mass properties was based on the complex method: field observations, laboratory tests and the RMR-system. Consequently, a good approximation for rock mass properties was constructed (see Table 2).

Properties of the aquifer-aquitard systems

\begin{tabular}{lrrr}
\hline Parameter & Cambrian sandstone & Cambrian clay & Vendian sandstone \\
\hline Density, Mg/m & $2.01-2.04$ & $2.05-2.30$ & $2.12-2.20$ \\
Density (dray), $\mathrm{Mg} / \mathrm{m}^{3}$ & $1.77-1.81$ & $1.74-1.94$ & $1.89-1.92$ \\
Porosity, \% & $28-31$ & $24-25$ & $28-31$ \\
Compressibility, $\mathrm{Pa}^{-1}$ & $2 \times 10^{-9}-3 \times 10^{-9}$ & $4 \times 10^{-9}-7 \times 10^{-10}$ & $6 \times 10^{-10}-5 \times 10^{-11}$ \\
Permeability, $(\mathrm{m} / \mathrm{s}) /(\mathrm{Pa} / \mathrm{m})$ & $1 \times 10^{-9}-6 \times 10^{-9}$ & $1 \times 10^{-16}-1 \times 10^{-17}$ & $8 \times 10^{-9}-1 \times 10^{-10}$ \\
Poisson's ratio & 0.25 & $0.20-0.30$ & 0.25 \\
Bulk modulus, GPa & $0.19-0.27$ & $0.15-0.90$ & $0.9-10.0$ \\
Shear modulus, GPa & $0.10-0.17$ & $0.07-0.40$ & $0.6-6.6$ \\
\hline
\end{tabular}

\section{Numerical modeling}

For the evaluation, the two-dimensional FLAC-program was used (FLAC 1995). It is an explicit finite difference code, which utilize the "Lagrangian" calculation scheme and explicit time stepping algorithm. FLAC has several built in material behavior models. In addition it contains groundwater and consolidation (fully coupled) models. Here, the methodology for rock mechanics modeling in data limited conditions were used (Starfield \& Cunsall 1988).

The problem assumes isotropic Darcy flow for water transport and elastic grain skeleton behavior. The water is assumed to flow in the vertical or horizontal direction only and there is no horizontal strain (one-dimensional problem). The applicability of one-dimensional model was demonstrated by spetial investigations (Arbeiter et al. 1982, Vallner \& Lutsar 1966).

\section{Results}

The results of Cambrian-Vendian aquifer-aquitard system are given in Figures 3 and 4 . Figure 3 shows the evolution of aquitard deformation with time. Analysis showed that the decrease of piesometric surface by $10 \mathrm{~m}$ gives the maximum plastic deformation $5 \mathrm{~mm}$. The total stress remains essentially constant through time (Figure 4). Under these circumstances, if the water pressure decreases, the effective stress increases by an equal amount. For the aquitard, the elastic deformation equals $0.65 \mathrm{~mm}$. 


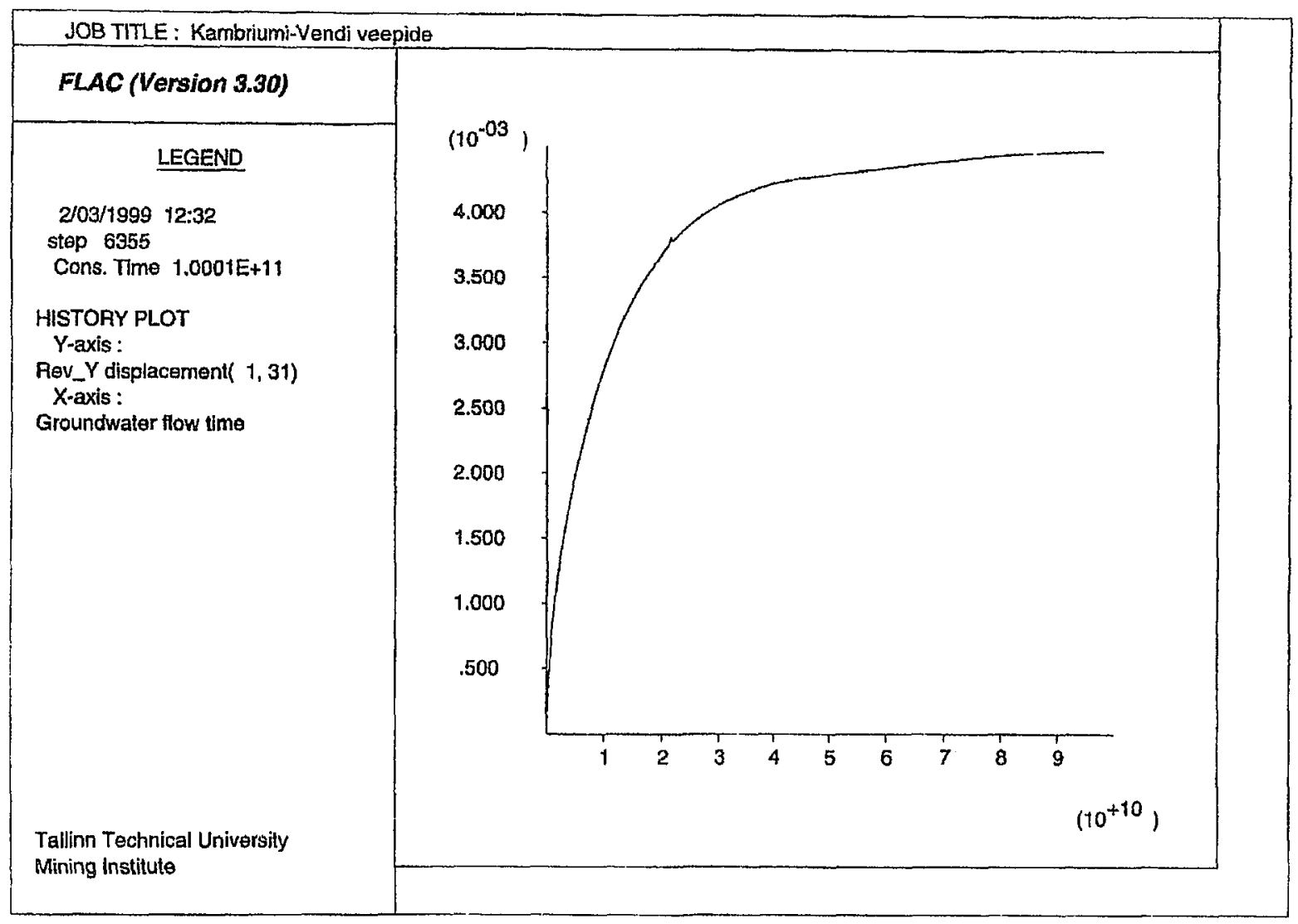

Figure 3. Evolution of vertical displacement of Cambrian-Vendian aquitard

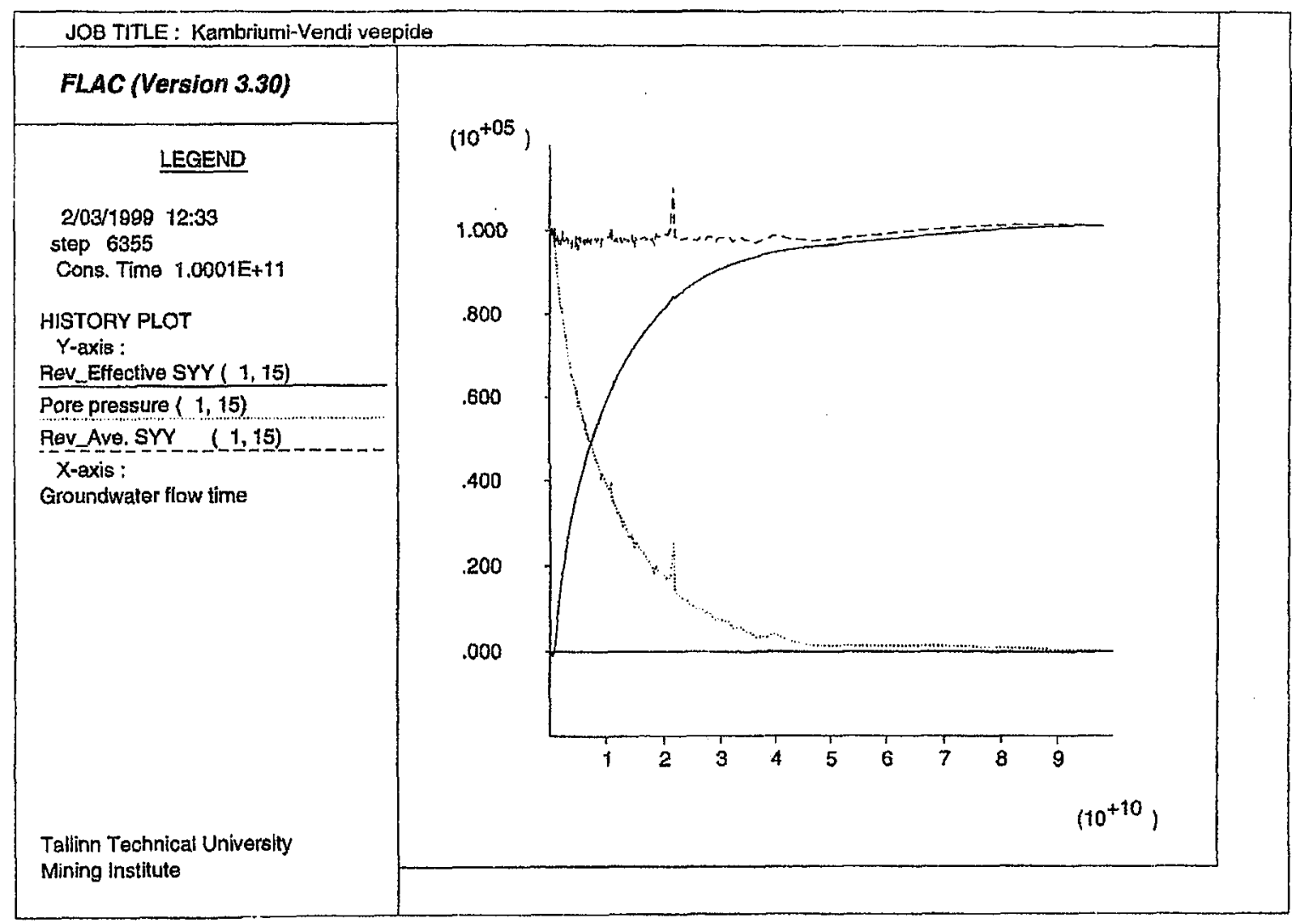

Figure 4. Evolution of pore pressure, effective and total stresses of Cambrian-Vendian aquitard 
The decrease of the water table of Ordovician-Cambrian aquifer-aquitard system by $1 \mathrm{~m}$ gives the maximum plastic deformation $0.8 \mathrm{~mm}$ and elastic $0.2 \mathrm{~mm}$.

Consequently, the surface subsidence and the Toompea Hill deformation do not exceed $7 \mathrm{~mm}$, owing to the great density and consolidated Vendian sandstones and clays. The obtined results and deep-seated graund benchmark are in the same magnitude. It is visible that the deformations are quite small and do not influence on the stability of the Toompea Hill.

\section{Conclusions and recommendations} made.

1. Sedimentary rocks represent Toompea Hill of the absolute height of $24 \mathrm{~m}$ and the territory of Tallinn. There are four aquifer-aquitard systems.

2. Toompea Hill deformation is connected with the surface subsidence of the territory of Tallinn. For the most part, surface subsidence depends on the behavior of Ordovician-Cambrian and Cambrian-Vendian aquifer-aquitard systems. The decrease of the water table of unconfined Ordovician-Cambrian and decrease of the piesometric surface of confined Cambrian-Vendian aquifer-aquitard systems cause the surface subsidence and consequently the Toompea Hill deformation.

3. By combining the field observations, laboratory tests and RMR-system, a good approximation for rock mass properties was constructed.

4. Preliminary analysis and the method for rock mechanics modeling in data limited conditions enabled to simplify and quicken the further modeling, improve the quality of the rock mass properties and investigations.

5. The elastic deformations of the layers cause the subsidence about $1 \mathrm{~mm}$, plastic -6 $\mathrm{mm}$. The total deformation is small and does not exceed $7 \mathrm{~mm}$, owing to the consolidated Vendian sandstone and clays.

6. This study was based on assumed properties of the rock mass and aquifer-aquitard systems. Other combinations of these parameters may give different results. Therefore, a sensitivity study is recommended to perform.

The research was financially supported by Estonian Science Foundation, grant No.2108, 1996-1998.

\section{REFERENCES}

1. Arbeiter R., Vallner L., Saapar L. and Savitsky L. 1982. Surface subsidence in Estonia. Water resources 2: 64-78. Moscow (in Russian).

2. FLAC, Fast Lagrangian Analysis of Continua. 1995. Version 3.3, Vol.1 and 2. Users Manual. Minneapolis: Itasca Consulting Group, Inc.

3. Frees R.A. and Cherry J.A. 1979. Groundwater. New Jersey: Prentice Hall, Englewood Cliffs.

4. Hoek E. and Brown E. 1980. Underground excavations in rock. London: Inc. of Mining and Metallurgy.

5. Starfield A.M. and Cundall P.A. 1988. Towards a methodology for rock mechanics modeling. Int. J.Rock Mech. Min. Sci. \& Geomech. Abstr. 25 (3): 99-106.

6. Vallner,L. and Lutsar,R. 1966. On the deformations of the Earth's surface on the territory of Tallinn. Proc. of the Second International Symposium on Recent Crystal Movements: 387-394. Helsinki. 